\title{
Ultrasonographic Appearance of Bovine Coxofemoral Luxation in Different Directions
}

\section{Kiyoshi Taguchi ${ }^{*}$, Katsunori Kudo², Takahide Suzuki ${ }^{2}$ and Koji Hyakutake ${ }^{3}$}

${ }^{1}$ Professor, Rakuno Gakuen University, Veterinary Medicine, Japan

${ }^{2}$ Ishikarichiku Agricultural Mutual Aid Association, Japan

${ }^{3}$ Iburi Agricultural Mutual Aid Association, Japan

\begin{abstract}
Coxofemoral luxation is common in cattle and prognosis is very guarded or poor. Diagnosis is generally based on thorough physical examination by identifying the structure of the hip, but an accurate diagnosis can be challenging, especially in heavy and recumbent cows because large muscle mass covering the pelvis and hip makes palpation of the bony structures difficult. In cattle practice, ultrasound has been widely used as an important ancillary test for a more accurate diagnosis and avoidance of unnecessary treatment. The purpose of this report is to describe ultrasonographic features of twenty two dairy cows (3-7 years) with coxofemoral luxation in three different directions. Five cows with craniodorsal, six with caudodorsal, and eleven with caudoventral luxation were examined ultrasonographically. Only three cows were able to stand and eleven exhibited asymmetry of the hip upon external examination of the hindlimbs. Sonographic findings on the dorsolateral view of the hip in standing and laterally recumbent cows invariably included the ball-shaped femoral head outside the acetabulum in dorsal luxations and heterechoic empty joint cavity of the acetabulum in ventral luxation. On the ventrodorsal view for dorsal recumbency with the frog-leg position, either luxated femoral head or empty acetabular cavity was visible in fifteen examined cows in the three different directions of luxation, but the femoral head of the caudodorsal luxation was translated caudoventrally to the acetabulum owing to severe soft tissue damage around the acetabulum. Transrectal ultrasonography of the caudoventral luxation revealed the ball of the femoral head in or ventral to the obturator foramen with varying amounts of fibrin deposit on it. Ultrasonography can be used to make a definitive diagnosis of coxofemoral luxation in three different directions in recumbent cows, as well as standing cows.
\end{abstract}

Keywords: Coxofemoral luxation; Ultrasonography; Bovine

\section{Introduction}

Luxation is relatively infrequent in bovine species because cattle generally have bulky muscle and strong periarticular ligaments and tendons, but cases do occur owing to sudden abnormal stresses in some joints [1]. One of the common sites is the coxofemoral joint, which has anatomic configurations that predispose to luxation. The relatively small head of the femur, minimal attachment of the femoral head to the pelvis, and shallow acetabulum allow the joint to dislocate by significant forces [1]. Falling with the hindlimbs in abduction related to postpartum events or estrus behavior can strain the joint resulting in the head of the femur becoming displaced from its normal position in the acetabulum [1-4]. Four directions of luxation, craniodorsal, caudoventral, caudodorsal, and cranioventral, in order of descending prevalence [1], have been described, but most cases are craniodorsal $[1,5,6]$.

The diagnosis of coxofemoral luxation in cattle is usually based on physical examination by identifying the structure of the hip $[1,3,6]$. However, this can be difficult, especially when a cow is down on the floor after falling, because the structures of the hip cannot be accurately palpated and evaluated in terms of the symmetry on each side [3].

Radiographs are useful to confirm the diagnosis and identify the associated damage such as pelvic fracture, proximal femoral fracture, and fracture of the femoral neck $[1,3,6-8]$. The procedure, however, often needs a high output machine, which may not be practicable in most ambulatory settings [3].

Ultrasonography, on the other hand, is a non-invasive and readily available test that can be used by a bovine practitioner at a farm. The ultrasonographic appearances of the normal coxofemoral joint in cattle
[9], craniodorsal coxofemoral luxation in calves [10], and coxofemoral subluxation in horses [11] have been described.

The purpose of this study was to describe the ultrasonographic appearance of eighteen dairy cows with coxofemoral luxation in different directions diagnosed in standing and recumbent cows.

\section{Materials and Methods}

Twenty two cows with an ultrasonographic diagnosis of coxofemoral luxation were identified in the records of cows referred to the Veterinary Medical Teaching Hospital, Rakuo Gakuen University, between June 2004 and August 2011. The luxation was unilateral and craniodorsal in five cows, caudodorsal in six, and caudoventral in eleven. Three of the cows with craniodorsal and caudodorsal luxation suffered fractures of the ilial body or greater trochanter of the femur. The records also included the anamnesis, signalment, physical examination findings according to the method of van Metre and others [12], results of diagnostic imaging, and postmortem findings if performed.

All cows were Holstein breed, ranging in age from three to seven

*Corresponding author: Kiyoshi Taguchi Ph.D., Professor, Rakuno Gakuen University, Veterinary Medicine, Bunkyoudai-Midorimachi582, Ebetsu, Hokkaido 069-8501, Japan, E-mail: k-tgc@rakuno.ac.jp

Received November 05, 2011; Accepted December 05, 2011; Published December 12, 2011

Citation: Taguchi K, Kudo K, Suzuki T, Hyakutake K (2011) Ultrasonographic Appearance of Bovine Coxofemoral Luxation in Different Directions. J Veterinar Sci Technol S3:003. doi:10.4172/2157-7579.S3-003

Copyright: ( 2011 Taguchi K, et al. This is an open-access article distributed under the terms of the Creative Commons Attribution License, which permits unrestricted use, distribution, and reproduction in any medium, provided the original author and source are credited. 
years. Six of the cows had calved within 10 days, five from 20 to 100 days previously, and twelve, including two dry cows, more than 100 days previously. According to referring veterinarians, lameness or recumbency was suspected of being caused by hip injury and associated with the onset of trauma due to slip and fall on a passageway in a tiestall barn or free-stall barn. All cows were referred for further diagnostic examination within 7 days from the onset of the condition.

\section{Ultrasonographic examination}

An ultrasound unit (Prosound 5000SV, Aloka, Tokyo) equipped with a $3.5 \mathrm{MHz}$ linear and a $7.5 \mathrm{MHz}$ linear transducer was used in the investigation. Transcutaneous dorsolateral ultrasonography of the coxofemoral joint was performed using the technique reported by Grubelink et al. [9] and Kofler [13] with the cow standing or laterally recumbent with the affected limb uppermost. In addition, ultrasonographic examination of the affected side of the pelvis was performed on the basis of local signs such as swelling and deformation. The hair over the hip area was clipped and ethyl alcohol and transmission gel were applied to the skin before the examination. The cow was sedated during the examination with intravenous xylazine (0.05-0.1 $\mathrm{mg} / \mathrm{kg}$ ) where appropriate. Following dorsolateral ultrasonography, fifteen cows that had been unable to rise were given spinal anesthesia by an intrathecal injection of a combination of xylazine $(0.05 \mathrm{mg} / \mathrm{kg})$ and lidocaine $(1 \mathrm{mg} / \mathrm{kg})$ from the lumbosacral space. The position of the cow then changed to dorsal recumbency with the limbs held in a fully flexed, abducted (frog-leg) position and transcutaneous ventrodorsal ultrasonography of both (affected and non-affected) coxofemoral joints was performed using a $3.5 \mathrm{MHz}$ transducer directed dorsally in the transverse and sagittal plane. Rectal examination was performed in nine cows that were suspected of ventral luxation and four of them underwent transrectal ultrasonography using a $7.5 \mathrm{MHz}$ linear transducer.

\section{Postmortem examination}

All cows were euthanized within several days after the diagnosis of coxofemoral luxation at the owner's request. Sixteen cows (four with craniodorsal, six with caudodorsal, and six with caudoventral luxation) underwent a postmortem examination and luxation-associated lesions, such as periarticular soft tissue trauma and fractures of the pelvis, were determined.

\section{Results}

\section{Clinical findings}

Only three cows with dorsal luxation were able to stand at the time of the examination. Abnormal location of the greater trochanter relative to the tuber ischii and tuber coxae was noted by physical examination in eleven cows and palpable crepitus in eighteen cows (Table 1).

\section{Ultrasonographic and postmortem findings}

All cows had complete dislocation of the femoral head during the ultrasonographic examination. Rupture of the joint capsule and femoral head ligament was found in all affected joints (sixteen cows) examined at necropsy (Table 1).

In craniodorsal luxation, the ball-shaped femoral head could be visualized craniodorsally outside the acetabulum as a hyperechoic crescentic line with the acoustic shadow distal to the femoral head on dorsolateral ultrasonography (Figure 1a). The joint cavity of the acetabulum, which was visualized as the result of the lack of the femoral head in the acetabulum, appeared as a heterechoic hollow with the underlying hyperechoic line representing the acetabular floor (fossa acetabuli) (Figure 1b). At the postmortem examination, the affected joint cavity was filled with blood, fibrin clot, and tissue fragments. Two cows underwent ventrodorsal ultrasonography and the joint cavity of the acetabulum was visible while the femoral head could not be seen in that view.

In caudodorsal luxation, the luxated femoral head was identified similar to that in craniodorsal luxation but located caudodorsal to the acetabulum on the dorsolateral view. The view also indicated the joint cavity of acetabulum in three of six cows, but in other three cows, it could not be seen because the proximal femur lay between the transducer and the acetabulum. On ventrodorsal ultrasonography, the femoral head, medial acetabular margin, and coxofemoral joint space could be observed in the normal side (Figure 2a) while the femoral head and the acetabulum were identified separately in the affected side (Figure $2 \mathrm{~b})$. The luxated femoral head was located outside the acetabulum and more superficially, caudally, and laterally than the contralateral normal one (Figure 3). Severe periarticular damage caudodorsally to caudoventrally around the acetabulum was observed in all six cows at the postmortem examination.

The femoral head luxated caudoventrally was not visible on dorsolateral ultrasonography, but the joint cavity of the acetabulum and the fossa acetabuli was clearly visible in all eleven cows with caudoventral luxation (Figure 4). On the ventrodorsal view, the affected femoral head was visualized caudomedially to the acetabulum. The ultrasonographic appearance around the luxated femoral head and the acetabulum was heterechoic, representing varying degrees of soft tissue trauma, which was confirmed at the autopsy. In all but one cow with caudoventral luxation, the femoral head was palpated in the obturator foramen by a rectal examination. During the transrectal ultrasonography, six of the cows, including the cow negative for the palpable femoral head, had the ball of the femoral head in or ventral to the obturator foramen where varying depths of homogeneous mass were present on the femoral head (Figure 5). The mass was confirmed to be a firm and thick fibrin deposit upon postmortem examination. The cow in which the femoral head had been palpated uncertainly

\begin{tabular}{|c|c|c|c|c|c|c|c|c|c|c|c|c|}
\hline \multirow{3}{*}{$\begin{array}{l}\text { Direction of } \\
\text { coxofemoral } \\
\text { luxation }\end{array}$} & \multirow{3}{*}{$\begin{array}{l}\text { No. of } \\
\text { cases }\end{array}$} & \multicolumn{3}{|c|}{ Clinical signs } & \multicolumn{5}{|c|}{ Ultrasound results } & \multicolumn{3}{|l|}{ Necropsy results } \\
\hline & & \multirow{2}{*}{$\begin{array}{l}\text { Able to } \\
\text { stand }\end{array}$} & \multirow{2}{*}{$\begin{array}{l}\text { Notable asymmetry } \\
\text { of the hip }\end{array}$} & \multirow{2}{*}{$\begin{array}{l}\text { Articular } \\
\text { crepitus }\end{array}$} & \multicolumn{2}{|c|}{$\begin{array}{l}\text { Transcutaneous } \\
\text { dorsolateral view }\end{array}$} & \multicolumn{2}{|c|}{$\begin{array}{l}\text { Transcutaneous } \\
\text { ventrodorsal view }\end{array}$} & \multirow{2}{*}{\begin{tabular}{|l|} 
Trans- \\
rectal view \\
BFH \\
\end{tabular}} & \multirow{2}{*}{$\begin{array}{l}\text { Rupture of joint } \\
\text { capsule and femoral } \\
\text { head ligament }\end{array}$} & \multirow{2}{*}{$\begin{array}{l}\text { Severe } \\
\text { periarticular } \\
\text { damage }\end{array}$} & \multirow{2}{*}{$\begin{array}{l}\text { Associated } \\
\text { fracture }\end{array}$} \\
\hline & & & & & $\mathrm{BFH}$ & AJC & $\mathrm{BFH}$ & AJC & & & & \\
\hline Craniodorsal & 5 & $2 * / 5 \dagger$ & $5 / 5$ & $5 / 5$ & $5 / 5$ & $5 / 5$ & $0 / 2$ & $2 / 2$ & NIA & $4 / 4$ & $1 / 4$ & $2 / 4$ \\
\hline Caudodorsal & 6 & $1 / 6$ & $2 / 6$ & $4 / 6$ & $6 / 6$ & $3 / 6$ & $6 / 6$ & $6 / 6$ & NIA & $6 / 6$ & $6 / 6$ & $1 / 6$ \\
\hline Caudoventral & 11 & $0 / 11$ & $4 / 11$ & $9 / 11$ & $0 / 11$ & $11 / 11$ & $7 / 7$ & $7 / 7$ & $6 / 6$ & $6 / 6$ & $4 / 6$ & $0 / 6$ \\
\hline
\end{tabular}

*Number of positive findings, †Number of cows evaluated, NIA No imaging attempted, BFH Diagnostic images of the ball of the femoral head, AJC Diagnostic images of the empty acetabular joint cavity

Table 1: Results of Clinical, Ultrasonographic, and Postmortem Examination of 18 Cows with Coxofemoral Luxation 
Citation: Taguchi K, Kudo K, Suzuki T, Hyakutake K (2011) Ultrasonographic Appearance of Bovine Coxofemoral Luxation in Different Directions. J Veterinar Sci Technol S3:003. doi:10.4172/2157-7579.S3-003

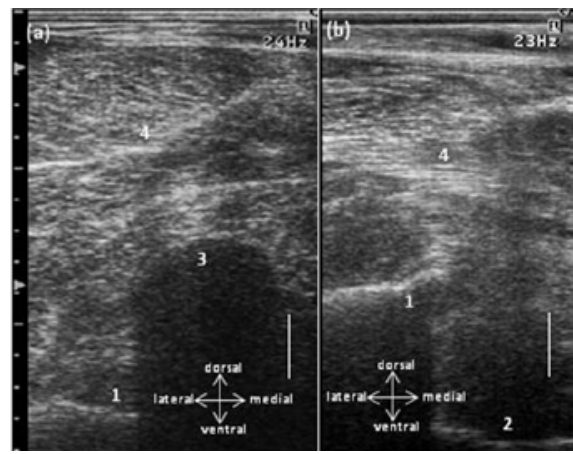

Figure 1: Transcutaneous ultrasonograms of a longitudinal-oblique section of the dorsolateral hip region showing (a) the luxated femoral head and (b) the corresponding acetabulum in craniodorsal coxofemoral luxation. 1 Acetabulum, 2 Fossa acetabuli, 3 Femoral head, 4 Gluteal muscle. Bar = $1 \mathrm{~cm}$.

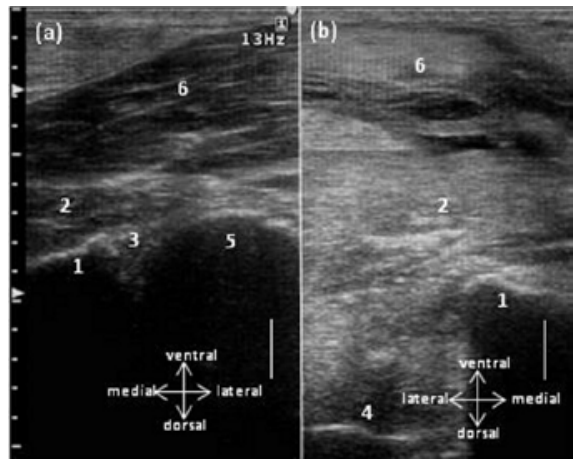

Figure 2: Transcutaneous ultrasonograms of a transverse section of the ventral hip joint showing (a) the normal appearance and (b) the contralateral acetabulum without the corresponding femoral head in caudodorsal coxofemoral luxation. 1 Acetabulum, 2 Adductor muscle, $3 \mathrm{CJ}$ coxofemoral joint, 4 Fossa acetabuli, 5 Femoral head, 6 Semimembranous muscle. Bar $=1 \mathrm{~cm}$.

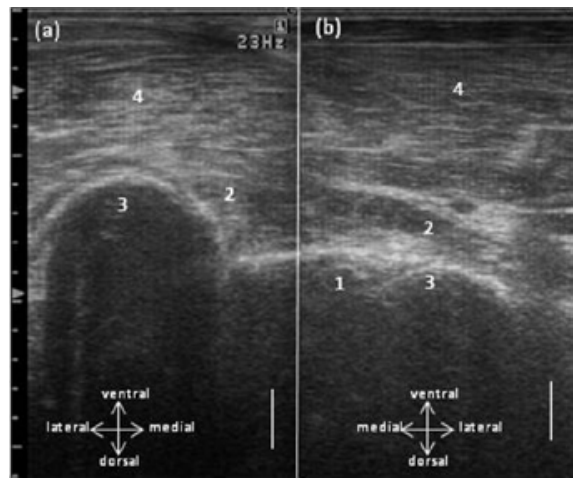

Figure 3: Transcutaneous ultrasonograms of a transverse section of the ventral hip region showing (a) the luxated femoral head and (b) the contralateral normal one in caudodorsal coxofemoral luxation. 1 Acetabulum, 2 Adductor muscle, 3 Femoral head, 4 Semimembranous muscle. Bar $=1$ $\mathrm{cm}$.

through the rectum had a large amount of fibrin deposit in the foramen (Figure 5c).

Ilial body fractures were present in two cows with craniodorsal and caudodorsal luxation (Table 1) and visible as a marked discontinuity and displacement of the bone surface of the ilial body cranial to the acetabulum on dorsolateral ultrasonography. One cow with craniodorsal luxation also suffered fracture of the greater trochanter with marked swelling of the outside of the thigh and ultrasonographic discontinuity of the bone contour of the greater trochanter.

\section{Discussion}

All cows with coxofemoral luxation in the three different directions showed in the ultrasonogram either the ball-shaped femoral head outside the acetabulum or the heterechoic joint cavity of the acetabulum on the transcutaneous dorsolateral view. Neither is found in a normal hip [9] because the ball part of a femoral head is received inside the socket part of the acetabulum. The ball of the femoral head dislocated dorsally was easily recognized by its appearance as a bright echogenic contour dorsal to the acetabulum, which was similar in appearance to that of calves [10]. Moreover, unlike in human infants [14] and canine neonates [15], nearly all the ultrasound waves did not penetrate the femoral head of cattle, which made an acoustic shadow distal to the femoral head. In contrast to dorsal luxations, the ventrally luxated femoral head could not be visualized on the dorsolateral view as the femoral head would be located in or ventral to the obturator foramen.

The other visual sign of the ultrasonogram of coxofemoral luxation was the heterechoic joint cavity of the acetabulum, which was due

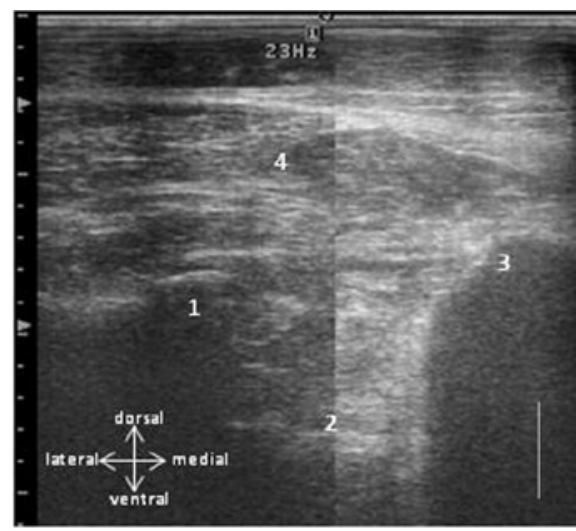

Figure 4: Transcutaneous ultrasonograms of a longitudinal-oblique section of the dorsolateral hip region showing the empty acetabular cavity in caudodorsal coxofemoral luxation. 1 Acetabulum, 2 Fossa acetabuli, 3 Femoral shaft, 4 Gluteal muscle. Bar $=1 \mathrm{~cm}$
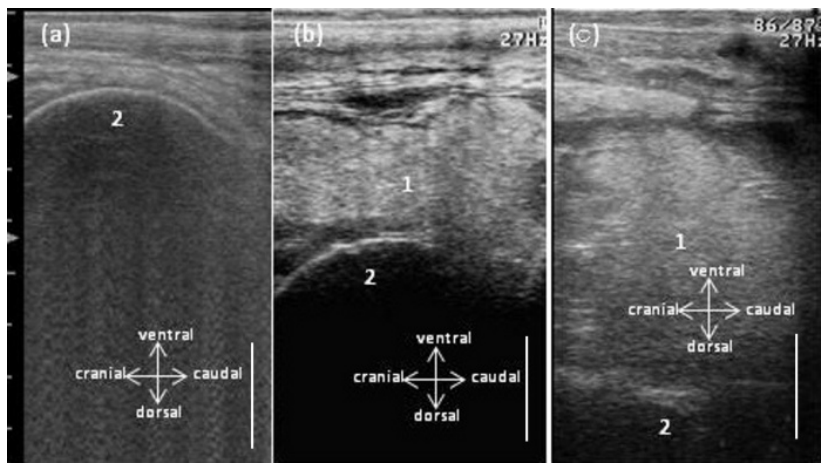

Figure 5: Transrectal ultrasonograms of the obturator foramen showing the caudoventrally luxated femoral head with (a) no, (b) relatively superficial, and (c) deep fibrin deposit. 1 Fibrin deposit, 2 Femoral head. Bar $=1 \mathrm{~cm}$. 
to fibrin clot and tissue fragments in the acetabulum instead of the femoral head. The floor of the acetabulum (fossa acetabuli) should also be visible as a hyperechoic line because the ultrasound waves pass through the clot in the acetabulum and reflect off the bony floor. These appearances of the acetabulum were observed in all cows with caudoventral and craniodorsal luxation but only three of six cows with caudodorsal luxation because of superimposed proximal femur. Thus, in the diagnosis of coxofemoral luxation, the ultrasonographic demonstration of the ball of the femoral head in dorsal luxations and the empty heterechoic acetabulum in ventral luxation can be a rapid and accurate assessment on the dorsolateral view of the hip.

On the ventrodorsal view in the dorsal recumbent position, an image of either the femoral head outside the acetabulum or the empty acetabular cavity was obtained in all examined cows in the three different directions of luxation. This suggested that the view could be an alternative for diagnosing the luxations in the recumbent cow if dorsolateral ultrasonography cannot produce the diagnostic image of luxation caused by marked swelling or subcutaneous emphysema in the dorsolateral hip. Moreover, the view had an additional merit in enabling evaluation of both hip joints at the same time although spinal anesthesia and casting were required to avoid the risk of being kicked by the cow during the examination.

Additionally, in dorsal recumbency with the frog-leg position, the femoral head of the caudodorsal luxation was translated caudoventrally to the acetabulum, which was revealed by ventrodorsal ultrasonography in this study. A similar finding has been reported in four cases of caudodorsal luxation diagnosed at the time of clinical examination, which were found as caudoventral luxation at autopsy due to severe periarticular soft tissue damage around the acetabulum [16]. The severe soft tissue damage in all six cows with caudodorsal luxation in the present study was also consistent with the translation of the femoral head. Therefore, it was suggested that caudodorsal luxation may typically have the most severe soft tissue damage around the acetabulum and that ventrodorsal ultrasonography may lead to a failure to recognize the original direction of the luxation.

Transrectal ultrasonography was helpful for diagnosis of caudoventral luxation by imaging the ball of the femoral head in the obturator foramen. The view often indicated fibrin deposit on the femoral head. The ultrasonographic appearance of the deposit was homoechoic unlike the fibrin clot filling the acetabulum because it was firm and thick, probably as a result of the hemorrhage and tissue fragments from the periarticular soft tissue being organized and compressed by the luxated femoral head. The transrectal ultrasonography was considered to be of importance if the presence of the femoral head in or ventral to the obtuator foramen is uncertain by rectal palpation owing to a large amount of deposit in the foramen.

Clinical diagnosis of coxofemoral luxation by the external

This article was originally published in a special issue, Veterinary Clinical Pathology handled by Editor(s). Dr. Diana L. Eubanks, Mississippi State University, USA; Dr. J. Jill Heatley, Texas A\&M University, USA examination of the hindlimbs was relatively easy to obtain in the standing cows with dorsal luxations. However, it could be difficult when the critical finding, such as asymmetry of the greater trochanter, was uncertain as the cow was down on the floor. In such cases, diagnosis could be readily obtained using ultrasound provided that the dorsolateral view of the hip was obtained in the lateral recumbent position. On the same view, the fracture of the ilial body with dorsal luxation could be diagnosed by identifying the disconnection of the bony contours of the fracture site similar in appearance to that of the horse [17]. The fracture of the greater trochanter with craniodorsal luxation could be also identified as defect of the bony contours of the fracture site.

\section{Conclusion}

In conclusion, the transcutaneous ultrasonographic appearance of coxofemoral luxation in three different directions includes either the ball-shaped femoral head outside the acetabulum or the heterechoic empty joint cavity of the acetabulum, which can be indicated on dorsolateral and ventrodorsal views. Transrectal ultrasound is also helpful for diagnosis of caudoventral luxation by imaging the femoral head in or ventral to the obturator foramen. Ultrasonography can be used to make a definitive diagnosis of coxofemoral luxation in three different directions in recumbent cows, as well as standing cows.

\section{References}

1. Greenough PR, MacCallum FJ, Weaver AD (1981) Dislocations and ligamentous injuries: Lameness in Cattle. (2ndedn) John Wright \& Sons, Bristol.

2. Rees HG (1989) Coxo-femoral dislocation in dairy cattle. Vet Rec 76: 362-364

3. Hull BL (1996) Fractures and luxations of the pelvis and proximal femur. Vet Clin North Am Food Anim Pract 12: 47-58.

4. Watson C (2007) Disease of the joints and bones: Lameness in Cattle Croswood Press, Marlborough.

5. Tulleners EP, Nunamaker DM, Richardson DW (1987) Coxofemoral luxations in cattle: 22 cases (1980-1985). J Am Vet Med Assoc 191: 569-574.

6. Larcombe MT, Malmo J (1989) Dislocation of the coxo-femoral joint in dairy cows. Aust Vet J 66: 351-354

7. Weaver AD (1969) Hip lameness in cattle. Vet Rec 85: 504-512.

8. Baird AN, Baird DK (1995) What is your diagnosis? Craniodorsal luxation of the left coxofemoral joint. J Am Vet Med Assoc 207: 39-40.

9. Grubelnik M, Kofler J, Martinek B, Stanek Ch (2002) [Ultrasonographic examination of the hip joint region and bony pelvis in cattle]. Berl Munch Tierarztl Wochenschr 115: 209-220.

10. Starke A, Herzog K, Sohrt J, Haist V, Hohling A et al. (2007) Diagnostic procedures and surgical treatment of craniodorsal coxofemoral luxation in calves. Vet Surg 36: 99-106.

11. Brenner S, Whicomb MB (2009) Ultrasonographic diagnosis of coxofemoral subluxation in horses. Vet Radiol Ultrasound 50: 423-428.

12. van Metre DC, Callan RJ, Garry FB (2001) Examination of the muscluloskeletal system in recumbent cattle. Compend Contin Educ Pract Vet 23: S5-S13.

13. Kofler J (2009) Ultrasonography as a diagnostic aid in bovine musculoskeletal disorders. Vet Clin North Am Food Anim Pract 25: 687-731.

14. Graf R (1983) New possibilities for the diagnosis of congenital hip joint dislocation by ultrasonography. J Pediatr Orthop 3: 354-359.

15. Greshake RJ, Ackerman N (1992) Ultrasound evaluation of the coxofemora joints of the canine neonate. Vet Radiol Ultrasound 33: 99-104.

16. Jubb TF, Malmo J, Brightling P, Anderson GA, Davis GM (1989) Prognostic factors for recovery from coxo-femoral dislocation in cattle. Aust Vet J 66: 354 358

17. Shepherd MC, Pilsworth RC (1994) The use of ultrasound in the diagnosis of pelvic fractures. Equine Vet Educ 6: 223-227. 